\title{
Journal Club: Relationship between carotid arterial properties and cerebral white matter hyperintensities
}

Jordan W. Squair, MSc, Thalia S. Field, MD, and Aaron A. Phillips, PhD

Neurology ${ }^{\circledR}$ 2018;90:338-340. doi:10.1212/WNL.0000000000004964
Correspondence

Dr. Phillips

aaron.phillips@ucalgary.

$\mathrm{ca}$

White matter hyperintensities (WMH) are generally diagnosed on brain MRI and are associated with risk of stroke, dementia, death, and functional impairment. ${ }^{1,2}$ Their progression appears to be insidious, and the detection of preclinical disease could provide the opportunity to aggressively manage risk factors (i.e., reduced thresholds to begin hypertension treatment, lowering blood pressure targets), increase monitoring frequency, and begin secondary prevention strategies in the case of silent infarcts (i.e., initiation of antiplatelet therapy with silent strokes, CT angiography as needed). Given that most people do not receive neuroimaging in the presymptomatic stage, an inexpensive, noninvasive test could help to identify those at risk. To date, potential vascular markers of cerebrovascular disease have focused on central arterial stiffness ${ }^{3}$; however, directly assessing the carotid arteries may be more relevant to cerebrovascular disease as this vessel serves as the primary conduit responsible for delivering blood to the brain.

This Journal Club article reports on a study from Rundek et al., ${ }^{4}$ who identified a novel noninvasive marker of white matter hyperintensities (WMH) within the cerebral cortex. The study presents an association between carotid diastolic diameter and $\mathrm{WMH}$, potentially highlighting a method to noninvasively detect WMH burden. The study also demonstrates that race-ethnicity is an important modifier of the association between carotid diastolic diameter and WMH. As such, this article has important implications for disease risk stratification, clinical trial design, and potentially preventative management.

\section{Hypothesis and design}

Is carotid artery stiffness strongly associated with WMH volume? To answer this important question, Rundek et al. leveraged the Northern Manhattan Stroke Study (NOMAS) ${ }^{1}$ to perform a cross-sectional study with the hypothesis that increased carotid artery stiffness would be associated with a greater volume of subclinical WMH across 3 major race-ethnic groups.

\section{Methods}

The experimental cohort was drawn from the ongoing NOMAS study examining the incidence of stroke and cognitive decline. ${ }^{1}$ Of the original 1,290 participants in the NOMAS MRI substudy since 2003, 1,166 individuals were identified as having both MRI and carotid ultrasound, and as such served as the sample for the current analysis. The primary outcome examined was WMH volume, measured as the volume of pixel intensity $>3.5$ SDs above the mean on a log-normal distribution of a fluid-attenuated inversion recovery MRI divided by total intracranial volume. The primary explanatory variable examined was carotid $\beta$-stiffness index (STIFF), calculated as follows:

$\underline{\ln (\text { systolic blood pressure - diastolic blood pressure })}$ 
STRAIN $=\frac{\text { carotid artery diameter systole }- \text { carotid artery diameter diastole }}{\text { carotid artery diameter diastole }}$

The associations between the explanatory variables and outcome were assessed using stepwise linear regression model development, whereby potential confounding factors (e.g., race-ethnicity, sex, age, educational attainment, cholesterol levels, alcohol use, smoking history, blood pressure, physical activity) were added to account for potential bias.

\section{Results}

The study sample consisted of 1,166 elderly (mean age $71 \pm 9$ years) individuals with diverse ethnicity (65\% Hispanic, $18 \%$ non-Hispanic black, $15 \%$ non-Hispanic white). In an unadjusted linear regression model carotid artery STIFF, diastolic diameter, and STRAIN were all significantly associated with WMH (all $p<0.002$ ). However, after adjustment for cerebrovascular disease risk factors, as well as carotid intima-media thickness and the presence of carotid plaque (i.e., model 3), only carotid artery diastolic diameter remained significantly associated with WMH $(\beta=0.09 ; p=0.001)$. The authors next found that race-ethnicity was a significant effect modifier. As such, they stratified their sample and found that both STRAIN and diastolic diameter were associated with greater WMH volume among Hispanic participants, but not among black or white participants. Finally, the authors examined a subsample of individuals with silent brain infarction (SBI) and found that carotid artery diastolic diameter was positively associated with the presence of SBI (odds ratio $1.31,95 \%$ confidence interval 1.07-1.61), indicating that for every millimeter increase in diastolic diameter, the odds of having an SBI were increased by $31 \%$.

\section{Interpretation}

Rundek et al. ${ }^{4}$ demonstrated that carotid artery diastolic diameter is associated with $\mathrm{WMH}$ in a large sample of ethnically diverse, elderly, but otherwise healthy individuals. The particular novelty is the association being preserved after covariation with known cerebrovascular disease risk factors. While the use of stepwise linear regression model development allowed the authors to account for some bias in their data, an important consideration in such a cross-sectional design is that further directional work is needed, and complete adjustment for important confounding variables is not possible. The authors conclude that further studies are required to determine if carotid ultrasound may serve as a useful tool for determining risk of WMH. The data did not reject the original null hypothesis, yet this well-done study has the following important potential implications:

1. Common carotid artery diastolic diameter may be a noninvasive tool to determine risk for cerebrovascular disease.

2. That Rundek et al. ${ }^{4}$ found this association in individuals largely without cerebrovascular disease suggests this marker may be used to detect disease while still in a preclinical state.

3. Large carotid artery diastolic diameter may be a consequence of downstream cerebrovascular microvessel disease, the ensuing rarefaction, and thus increased resistance to cerebral blood inflow.

4. Conversely, directional causality may be reversed. Cerebrovascular microvessel disease, and therefore $\mathrm{WMH}$, may be a consequence of a distended carotid artery and the resulting changes in blood flow characteristics (e.g., pulsatility, shear patterns).

5. Increased common carotid artery diameter and increased WMH may follow a common pathologic sequela related to various arteriosclerotic and fibrotic mechanisms.

6. Ethnicity appears to be an important factor in the relationship between carotid artery diameter and $\mathrm{WMH}$, and therefore deserves further study.

7. $\beta$ Stiffness did not survive correction for known cerebrovascular risk factors, suggesting future clinical studies should be cautious in its use for patient stratification.

\section{Strengths of this study}

There are several strengths of this study related to its study design and research question:

1. This is the largest study to examine carotid artery diameter and its association with potential cerebrovascular disease, as measured using WMH.

2. The finding that ethnicity was a significant effect modifier demonstrates the importance of this consideration when examining associations between risk factors and cardiovascular disease.

3. Extensive participant data, such as alcohol use, physical activity, and presence of carotid plaques, allowed for clear elucidation of the independent relationship between carotid diastolic diameter and WMH.

4. The relatively advanced age of the cohort studied is ideal, in that this age group (i.e., older than 65) represents the nadir above which the risk of cerebrovascular disease sharply increases. ${ }^{5}$

5. Importantly, these authors corrected for the underlying blood pressure during the measurement of carotid diameter. Blood pressure exerts a direct positive effect on carotid artery diameter, and those with higher blood pressure will likely have greater carotid diameter, as well as increased $\mathrm{WMH}^{6-8}$ Statistic covariation for this confounder helped to clarify the results. It would of course have been optimal to also include the chronicity of hypertension to include the duration of exposure, which may also affect the association.

\section{Study limitations}

Weaknesses of the study are as follows:

1. The time between the MRI and the ultrasound measurements was up to 4 years, and this may lead to an 
overestimation of the association between carotid artery stiffness and $\mathrm{WMH}$ volume.

2. It would have been optimal to directly compare the association between pulse wave velocity and WMH. This comparison was alluded to in the introduction but not addressed in the study itself.

3. The authors present a nicely constructed linear model to account for several confounding factors. However, this model is applied to numerous explanatory variables, within separate models, and as such would benefit from multiple hypothesis correction. While this correction would not change the results or interpretation for the association between diameter and WMH for the entire sample $(p=0.001,>0.003$, according to the Bonferroni method), it may alter the stratified sample analyses.

4. The measurement of the outcomes (i.e., segmentation of images to determine WMH volume) may have some variability due to operator-dependent features (i.e., determining the border between CSF and parenchyma). In addition, the independent variable (i.e., carotid features on ultrasound) requires a high amount of intrarater reliability to limit measurement error.

Despite these limitations, the authors provide a potentially useful, noninvasive, and cost-effective method to estimate WMH burden. Further, the authors make an astute observation that validation of this method within a clinical population would add significant strength to their statements. This validation will be important, and extrapolation to many clinical populations is crucial, particularly due to the significant dependence of carotid diameter on the prevailing hemodynamic state during assessments. Of course, as is the case with all cross-sectional evaluations, prospective studies are needed to examine the possible directionality of this association, and chronicity of hypertension should be accounted for.

As indicated by the authors, the present data demonstrate that ultrasound-derived carotid dimensions may be a useful tool to noninvasively predict WMH in clinical populations with elevated cerebrovascular disease risk; however, causal directional data are still needed. One example where this may be a useful tool is the management of secondary consequences of spinal cord injury, where both carotid dimensions and cortical white matter are altered, and patients may benefit from early aggressive intervention (i.e., early intervention, reduced treatment thresholds, reduced treatment targets), as well as increased monitoring frequency. ${ }^{7,9,10}$ This, in combination with the aforementioned strengths, make this article an important contribution to the discovery and validation of noninvasive tools to assess cerebrovascular health.

\section{Author contributions}

J.W. Squair: drafting/revising the manuscript, analysis or interpretation of data. T.S. Field: revising the manuscript, interpretation of data. A.A. Phillips: drafting/revising the manuscript, analysis or interpretation of data.

\section{Study funding}

No targeted funding reported.

\section{Disclosure}

The authors report no disclosures relevant to the manuscript. Go to Neurology.org/N for full disclosures.

\section{References}

1. Debette S, Markus HS. The clinical importance of white matter hyperintensities on brain magnetic resonance imaging: systematic review and meta-analysis. BMJ 2010; 341:c3666.

2. Prabhakaran S, Wright CB, Yoshita M, et al. Prevalence and determinants of subclinical brain infarction: the Northern Manhattan Study. Neurology 2008;70: 425-430.

3. Singer J, Trollor JN, Baune BT, Sachdev PS, Smith E. Arterial stiffness, the brain and cognition: a systematic review. Ageing Res Rev 2014;15:16-27.

4. Rundek T, Della-Morte D, Gardener H, et al. Relationship between carotid arterial properties and cerebral white matter hyperintensities. Neurology 2017;88: 2036-2042.

5. Feigin VL, Lawes CMM, Bennett DA, Anderson CS. Stroke epidemiology: a review of population-based studies of incidence, prevalence, and case-fatality in the late 20th century. Lancet Neurol 2003;2:43-53.

6. Roman MJ, Pickering TG, Schwartz JE, Pini R, Devereux RB. Relation of arterial structure and function to left ventricular geometric patterns in hypertensive adults. J Am Coll Cardiol 1996;28:751-756.

7. Phillips AA, Krassioukov AV, Ainslie PN, Cote AT, Warburton DER. Increased central arterial stiffness explains baroreflex dysfunction in spinal cord injury. J Neurotrauma 2014;31:1122-1128.

8. Dufouil C, de Kersaint-Gilly A, Besançon V, et al. Longitudinal study of blood pressure and white matter hyperintensities: the EVA MRI Cohort. Neurology 2001; 56:921-926.

9. Wecht JM, Radulovic M, Lessey J, Spungen AM, Bauman WA. Common carotid and common femoral arterial dynamics during head-up tilt in persons with spinal cord injury. J Rehabil Res Dev 2004;41:89-94.

10. Freund P, Weiskopf N, Ashburner J, et al. MRI investigation of the sensorimotor cortex and the corticospinal tract after acute spinal cord injury: a prospective longitudinal study. Lancet Neurol 2013;12:873-881. 


\section{Neurology}

\section{Journal Club: Relationship between carotid arterial properties and cerebral white matter hyperintensities}

Jordan W. Squair, Thalia S. Field and Aaron A. Phillips

Neurology 2018;90;338-340

DOI 10.1212/WNL.0000000000004964

\section{This information is current as of February 12, 2018}

\section{Updated Information \&} Services

References

Subspecialty Collections

Permissions \& Licensing

Reprints including high resolution figures, can be found at: http://n.neurology.org/content/90/7/338.full

This article cites 10 articles, 5 of which you can access for free at: http://n.neurology.org/content/90/7/338.full\#ref-list-1

This article, along with others on similar topics, appears in the following collection(s):

All Cerebrovascular disease/Stroke

http://n.neurology.org/cgi/collection/all_cerebrovascular_disease_strok e

Cohort studies

http://n.neurology.org/cgi/collection/cohort_studies

MRI

http://n.neurology.org/cgi/collection/mri

Prognosis

http://n.neurology.org/cgi/collection/prognosis

Ultrasound

http://n.neurology.org/cgi/collection/ultrasound

Information about reproducing this article in parts (figures,tables) or in its entirety can be found online at:

http://www.neurology.org/about/about_the_journal\#permissions

Information about ordering reprints can be found online:

http://n.neurology.org/subscribers/advertise

Neurology ${ }^{\circledR}$ is the official journal of the American Academy of Neurology. Published continuously since 1951, it is now a weekly with 48 issues per year. Copyright () 2018 American Academy of Neurology. All rights reserved. Print ISSN: 0028-3878. Online ISSN: 1526-632X.

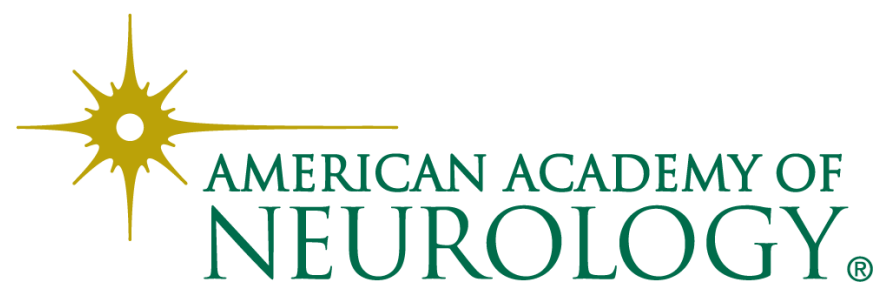

